\title{
A caspase-resistant mutant of PKC- $\delta$ protects keratinocytes from UV-induced apoptosis
}

\author{
AM D'Costa ${ }^{1}$ and MF Denning ${ }^{*, 2}$ \\ ${ }^{1}$ Division of Molecular and Cellular Biochemistry, Cardinal Bernardin Cancer \\ Center, Loyola University Medical Center, Maywood, IL, USA \\ 2 Department of Pathology, Cardinal Bernardin Cancer Center, Loyola \\ University Medical Center, Maywood, IL, USA \\ * Corresponding author: MF Denning, Cardinal Bernardin Cancer Center, Room \\ 310, Loyola University Medical Center, 2160 S. First Avenue, Maywood, IL \\ 60153, USA. Tel: 708327 3358; Fax: 708327 3158; E-mail: mdennin@lumc.edu
}

Received 24.6.04; revised 10.11.04; accepted 17.11.04; published online 24.12.04 Edited by B Osborne

\begin{abstract}
Keratinocyte apoptosis induced by UV radiation is a major induction of apoptosis by UV radiation, as well as a variety of genotoxic stimuli, involves the activation of PKC- $\delta$ by caspase-3-mediated cleavage in its hinge region, thus generating a constitutively active catalytic fragment. To from the mitochondria and the loss of Mcl-1, a key Thus, the cleavage and activation of PKC- $\delta$ are critical components of UV-induced apoptosis in human keratinocytes, and the inactivation of PKC- $\delta$ can promote the survival of keratinocytes exposed to UV radiation.

Cell Death and Differentiation (2005) 12, 224-232.

doi:10.1038/sj.cdd. 4401558

Published online 24 December 2004
\end{abstract} protective mechanism from skin photocarcinogenesis. The determine the role of PKC- $\delta$ cleavage in UV apoptosis signaling, we introduced a caspase-resistant PKC- $\delta$ mutant (D330A) into human keratinocytes by retrovirus transduction. Overexpression of PKC- $\delta$ (D330A) protected keratinocytes from UV-induced apoptosis and enhanced long-term survival. PKC- $\delta$ (D330A) partially prevented the release of cytochrome $c$ antiapoptotic protein downregulated during UV apoptosis.

Keywords: $\mathrm{Mcl}-1$; PKC- $\delta$; UV radiation; keratinocytes; apoptosis

Abbreviations: UV, ultraviolet; PKC, protein kinase C

\section{Introduction}

Ultraviolet (UV)B radiation from the sun is the primary carcinogen responsible for the formation of nonmelanoma skin cancer, by far the most common type of cancer in the US. Apoptosis is a major tumor suppressor mechanism that eliminates damaged keratinocytes at risk of becoming transformed from the epidermis. UV radiation triggers apoptosis in human keratinocytes by multiple signaling pathways. UV radiation primarily activates the intrinsic or mitochondrial pathway by causing the release of cytochrome $c$ from the mitochondria. ${ }^{1}$ Cytochrome $c$ forms a apoptosome complex with Apaf-1 and caspase-9 triggering the activation of caspase-9. In keratinocytes, activated caspase-9 is a critical upstream caspase required for initiating UV apoptosis. ${ }^{2}$ However, UV radiation also triggers the clustering and activation of membrane receptors such as Fas and tumor necrosis factor receptor. ${ }^{3-5}$ Caspase- 3 is an effector caspase that can be activated by both caspase- 8 and caspase- 9 . Activation of the effector caspases leads to cleavage of numerous cellular proteins that trigger nuclear breakdown, loss of mitochondrial membrane potential, and cell death.

PKC- $\delta$ is one of over 40 known caspase substrates and is cleaved specifically by caspase-3..$^{1,6}$ This cleavage takes place in the hinge region (V3) of PKC- $\delta$ at the caspase-3 recognition sequence $\left(\mathrm{DMQD}^{330} / \mathrm{N}\right)$. The cleavage of $\mathrm{PKC}-\delta$ is common to the death effector pathways of diverse apoptotic stimuli, including UV radiation, ionizing radiation, DNA-damaging drugs, TNF- $\alpha$, and anti-Fas antibody. There is a form of PKC$\delta$ (PKC- $\delta$ II) which is insensitive to caspase- $3,{ }^{7}$ thus cleavage sensitivity can be regulated at the level of RNA splicing. While other PKC isoforms (PKC $\varepsilon, \theta, \zeta$ ) can undergo proteolysis by caspases, PKC- $\delta$ was the only isoform activated by this mechanism in keratinocytes during UV radiation-induced apoptosis. ${ }^{8,9}$ PKC- $\delta$ itself can also initiate apoptosis in keratinocytes involving direct interaction with the mitochondria and alterations of mitochondrial functions. ${ }^{10,11}$ Overexpression of the catalytic domain of PKC- $\delta$ is sufficient to cause apoptosis in normal keratinocytes, HaCaT cells, HeLa, NIH3T3 and COS1 cells, suggesting that PKC- $\delta$ is an important effector of apoptosis. ${ }^{6,11,12}$ Inhibition of PKC activity by the general PKC inhibitor GF109293X partially blocked UV-induced cleavage and activation of PKC- $\delta$, pro-caspase- 3 , and pro-caspase-8, and thus rescued keratinocytes from UV-induced apoptosis, indicating that PKC is involved in a positive feedback loop that amplifies the apoptotic response of keratinocytes to UV. ${ }^{11,13}$

In this study, we examined the mechanism of protection from UV-induced apoptosis in human keratinocytes by selectively blocking the caspase-3-mediated cleavage of PKC- $\delta$. Our results demonstrate that inhibition of PKC- $\delta$ activation by caspase cleavage significantly inhibits apoptosis induced by UV radiation and promotes cell survival. Blocking PKC- $\delta$ cleavage inhibited the downregulation of Mcl-1 and the release of cytochrome $c$ from the mitochondria, thus preventing the feedback activation of caspases. This indicates that the positive feedback mediated by cleavage-induced activation of PKC- $\delta$ is required for UV-induced apoptosis in normal human keratinocytes.

\section{Results}

\section{PKC- $\delta(\mathrm{D} 330 \mathrm{~A})$ is resistant to cleavage by caspase-3}

PKC- $\delta$ is cleaved by caspase- 3 in its hinge region at the recognition motif DMQD ${ }^{330}$. To create a mutant PKC- $\delta$ that is 
resistant to cleavage and activation by caspase-3, we mutated the aspartic acid at 330 to alanine (D330A) as shown schematically in Figure 1a. The full-length wild-type and mutant forms of PKC- $\delta$ were detectable as a $78-\mathrm{kDa}$ band in Figure 1b. Incubation of cell lysates containing the wild-type PKC- $\delta$ with active recombinant caspase-3 generated a 43kDa domain catalytic product. In contrast, the PKC- $\delta$ (D330A) mutant was not cleaved by recombinant caspase-3. Weak, nonspecific $45 \mathrm{kDa}$ bands were also detected in all lanes.

\section{Activation of PKC- $\delta$ by UV is blocked by overexpression of PKC- $\delta$ (D330A)}

To determine if the noncleavable PKC- $\delta(D 330 A)$ is resistant to activation in cells with caspases activated, we overexpressed $\mathrm{PKC}-\delta$ (D330A) in normal human keratinocytes by retroviral transduction and exposed the cells to UV radiation. As shown in Figure 2, PKC- $\delta$ activity was induced over 50 -fold $18 \mathrm{~h}$ after UV irradiation in vector-infected control cells (Linker), but this induction was inhibited by $64.3 \%$ in PKC$\delta$ (D330A)-expressing cells. Thus, PKC- $\delta$ (D330A) can act as a dominant inhibitor of PKC- $\delta$ activation by UV. In contrast, PKC- $\delta$ (D330A) had no effect on the activation of PKC- $\delta$ by TPA treatment of cells (Figure $2 b$ ), indicating that PKC$\delta$ (D330A) selectively inhibited the caspase-3-dependent PKC- $\delta$ activation.

\section{Normal human keratinocytes are protected from UV-induced apoptosis}

Keratinocytes infected with control Linker virus or PKC$\delta(\mathrm{D} 330 \mathrm{~A})$ virus had a typical cobblestone appearance as seen in Figure $3 a$. When Linker virus-infected keratinocytes underwent UV-induced apoptosis, they became rounded, detached and floated in the media. PKC- $\delta$ (D330A)-infected

a
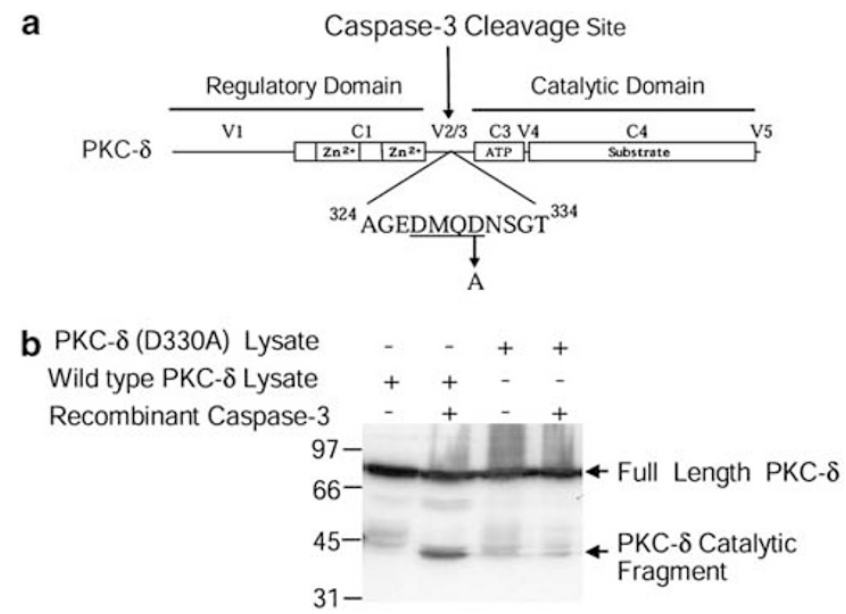

Figure 1 Effect of recombinant caspase-3 on PKC- $\delta$ and PKC- $\delta$ (D330A) cleavage. (a) Schematic representation of PKC- $\delta$ and the D330A mutation at the caspase- 3 cleavage site in the hinge domain of PKC- $\delta$. (b) Lysates from cells infected with wild-type PKC- $\delta$ virus or PKC- $\delta$ (D330A) virus were incubated with $200 \mathrm{ng}$ recombinant caspase- 3 for $1 \mathrm{~h}$ as indicated and analyzed by Western blot for PKC- $\delta$. Note that the wild-type PKC- $\delta$ was cleaved by caspase-3, but PKC$\delta(\mathrm{D} 330 \mathrm{~A})$ was not
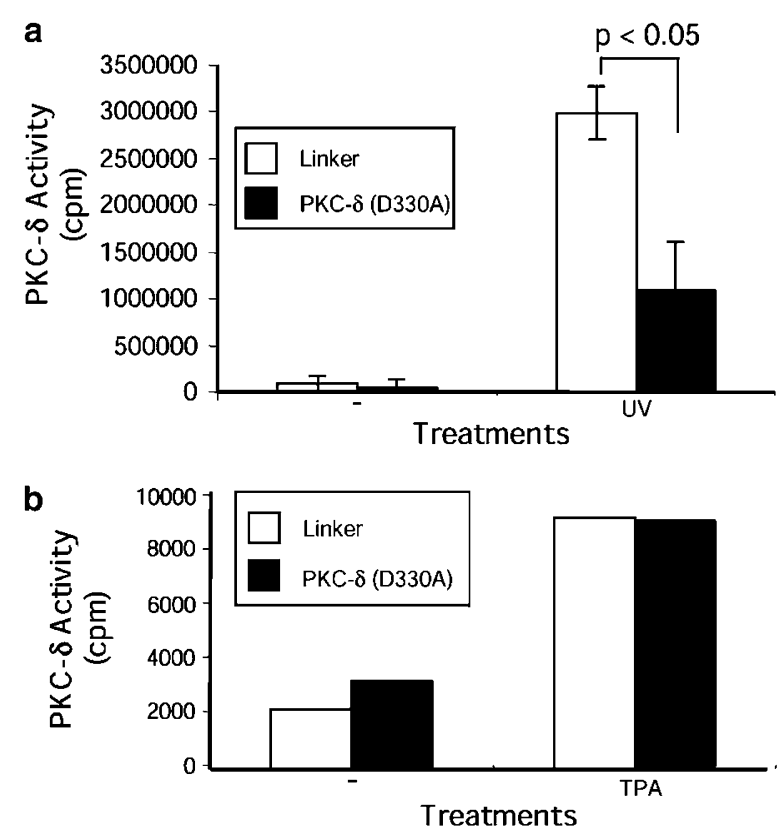

Figure 2 PKC- $\delta(\mathrm{D} 330 \mathrm{~A})$ inhibits the activation of PKC- $\delta$ by UV, but not by TPA. (a) Keratinocytes were infected with control (Linker) or PKC- $\delta$ (D330A) virus, and irradiated with $30 \mathrm{~mJ} / \mathrm{cm}^{2}$ UV. PKC- $\delta$ was immunoprecipitated from the cell lysates $18 \mathrm{~h}$ after UV exposure, and the enzyme activity assayed. Note the significant inhibition of UV-induced PKC- $\delta$ activity by PKC- $\delta$ (D330A) $(n=2$, $P<0.05$ ) with error bars denoting range. (b) Keratinocytes were treated with $2 \mu \mathrm{M}$ TPA for $15 \mathrm{~min}$. PKC- $\delta$ was immunoprecipitated from the cell lysates and the enzyme activity was assayed. This experiment was performed twice with similar results

keratinocytes were protected from morphological UV-induced cell death as compared to Linker-infected controls, although an approximately $50 \%$ decrease in the cell number was observed. This decrease in cell number may be due to a generalized cell cycle arrest induced by UV in the PKC$\delta(\mathrm{D} 330 \mathrm{~A})$-expressing cells, or may reflect the incomplete protection from apoptosis by $\mathrm{PKC}-\delta$ (D330A), which was also on the order of $50 \%$ (Figure 4$)$. PKC- $\delta(D 330 A)$-infected keratinocytes had more than 10-fold overexpression of the mutant form of PKC- $\delta$ as compared to endogenous PKC- $\delta$ (Figure 3b).

The survival of keratinocytes exposed to UV was also enhanced by PKC- $\delta$ (D330A) expression. As shown in Figure $3 c$, the number of viable cells at 1,3 , and 7 days after UV exposure was higher in the cells expressing PKC$\delta(\mathrm{D} 300 \mathrm{~A})$ than Linker-infected control cells $\left({ }^{\star} P<0.05\right)$. While the cells did not proliferate significantly while remaining in the same dish due to apoptotic cellular debris, the keratinocytes did grow after day 3 upon replating into larger dishes. Note that the growth rate of the cells was not increased, but only the overall long-term survival. As a positive control, Bcl- $\mathrm{x}_{\mathrm{L}}$ infection also enhanced the survival and growth of UVirradiated keratinocytes cells. These results indicate that inhibition of PCK- $\delta$ cleavage and activation does not simply delay apoptosis, but affords a significant growth advantage.

To determine whether PKC- $\delta$ (D330A)-infected keratinocytes were protected from apoptosis induced by UV, we performed propidium iodide and Annexin $\mathrm{V}$ staining of 
a
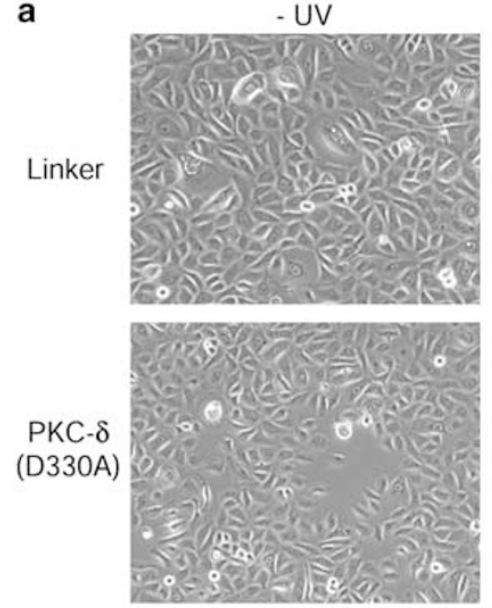

b

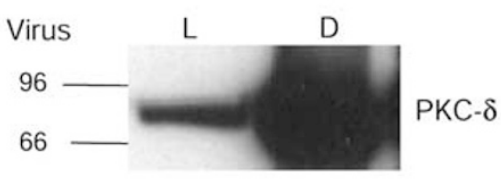

45
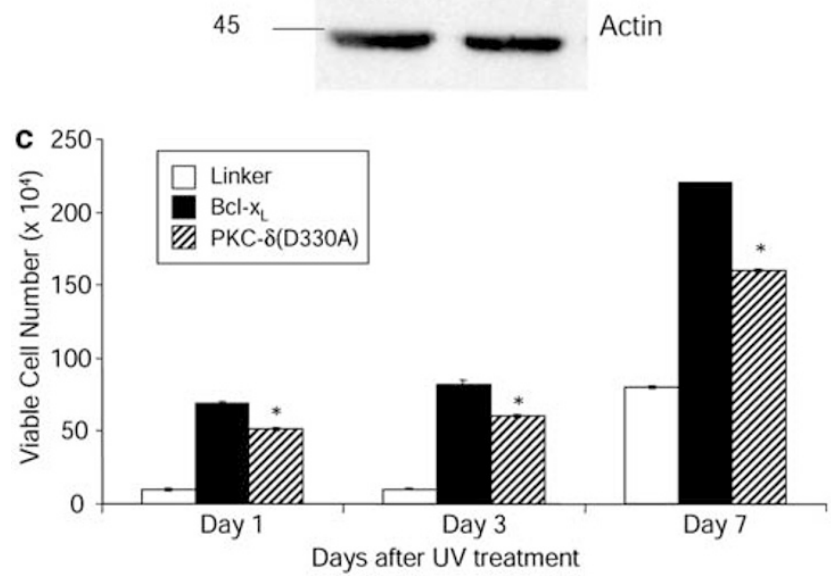

Figure 3 PKC- $\delta(\mathrm{D} 330 \mathrm{~A})$ protects normal keratinocytes from UV-induced cell death. (a) Keratinocytes were infected with either LZRS-Linker control virus or PKC- $\delta$ (D330A) virus. At 2 days after infection, the cells were exposed to $30 \mathrm{~mJ} /$ $\mathrm{cm}^{2}$ of UV. At $18 \mathrm{~h}$ after UV exposure, cells were photographed. (b) Total cell lysates were prepared from keratinocytes infected with Linker (L) virus or PKC$\delta(\mathrm{D} 330 \mathrm{~A})$ virus, and blotted for PKC- $\delta$ and Actin. (c) Equal numbers of keratinocytes were infected with either Linker control, Bcl- $x_{\mathrm{L}}$, or PKC- $\delta(\mathrm{D} 330 \mathrm{~A})$ virus, and 2 days later exposed to $30 \mathrm{~mJ} / \mathrm{cm}^{2}$ UV. After 1 day, the media was changed and the cells were grown in the same wells until day 3 when they were replated into larger dishes. Viable cell counts were taken on the indicated days after irradiation. The asterisks denote statistically significant different viable cell numbers compared to the Linker control at each time point $\left(n=2,{ }^{*} P<0.05\right)$ with error bars denoting range. Similar results were obtained in an independent experiment

keratinocytes $18 \mathrm{~h}$ after UV exposure. Figures $4 \mathrm{a}$ and $\mathrm{b}$ show that in keratinocytes infected with PKC- $\delta(\mathrm{D} 330 \mathrm{~A})$, UVinduced apoptosis was inhibited $62 \%$, as measured by propidium iodide staining from three independent experiments $(P<0.05)$. Annexin V/PI staining was also performed to quantitate early and late apoptotic events. PKC- $\delta$ (D330A) was able to protect keratinocytes from UV-induced apoptosis as compared to Linker-infected controls. As shown in Figures 4c and $\mathrm{d}$, the protection from UV-induced apoptosis was $68.1 \%$ by Annexin $V$ staining from three independent experiments $(P<0.05)$.

\section{PKC- $\delta(D 330 A)$ inhibits the release of cytochrome $c$ in response to UV}

Cytochrome $c$ release from the mitochondria is an early triggering event in UV apoptosis, while PKC- $\delta$ cleavage by caspase-3 is a late effector event. As shown in Figure 5, cytochrome $c$ is elevated $\sim 5$-fold in the cytoplasmic fraction following UV irradiation, indicating release from the mitochondria. UV-induced cytochrome $c$ release was partially blocked by overexpressing PKC- $\delta$ (D330A). The inhibition of cytochrome $c$ release by PKC- $\delta$ (D330A) was reproducible, and an average of four experiments is shown in Figure $5 b(n=4$, $P<0.05)$. The release of cytochrome $c$ from mitochondria was also blocked by the antiapoptotic Bcl- $\mathrm{x}_{\mathrm{L}}$ (data not shown).

\section{PKC- $\delta(D 330 A)$ inhibits caspase-3 activity in response to UV}

Since the caspase cleavage-resistant PKC- $\delta(\mathrm{D} 330 \mathrm{~A})$ was able to reduce cytochrome $c$ release, we determined the activity of caspase-3 using the fluorogenic substrate AcDEVD-AFC and performed Western blots for caspases- 3 and cleaved caspase-9 (Figure 6). PKC- $\delta$ (D330A) significantly inhibited caspase-3 activity $(66 \%)$ in response to UV exposure. This result was obtained from three independent experiments $(P<0.05)$. PKC- $\delta(\mathrm{D} 330 \mathrm{~A})$ also partially prevented the cleavage of full-length caspase- 3 and cleaved caspase- 9 in response to UV. In the upper panel of Figure $6 \mathrm{~b}$, the full-length form of caspase-3 was detected as a $32-\mathrm{kDa}$ band. In the middle panel of Figure $6 \mathrm{~b}$, the cleaved product of caspase-9 was detected as a $17-\mathrm{kDa}$ band. PKC- $\delta$ (D330A) was able to inhibit caspase-9 cleavage since the level of activated caspase- 9 was three-fold less in PKC- $\delta$ (D330A) than Linker-infected controls. Actin was used as a loading control in the lower panel of Figure $6 \mathrm{~b}$. Taken together, these results indicate that $\mathrm{PKC}-\delta$ cleavage is important for amplification of the caspase cascade in the UV-death effector pathway.

\section{PKC- $\delta(\mathrm{D} 330 \mathrm{~A})$ protects keratinocytes from UV- induced loss of mitochondrial membrane potential}

To determine whether PKC- $\delta$ (D330A) was able to protect human keratinocytes from UV-induced loss of mitochondrial membrane potential, we performed Rhodamine 123 staining. The loss of mitochondrial membrane potential is an indicator of cells undergoing the terminal phase of UV-induced apoptosis and is dependent on caspase activity. Figure 7 shows that PKC- $\delta$ (D330A) protected keratinocytes from UVinduced loss of mitochondrial membrane potential as compared to Linker-infected controls. As shown in Figure 7a (a representative experiment), $50 \%$ of Linker-infected control cells had lost their mitochondrial membrane potential in response to UV compared to $17.6 \%$ in PKC- $\delta(\mathrm{D} 330 \mathrm{~A})$ infected keratinocytes. Figure $7 \mathrm{~b}$ shows that the percentage 

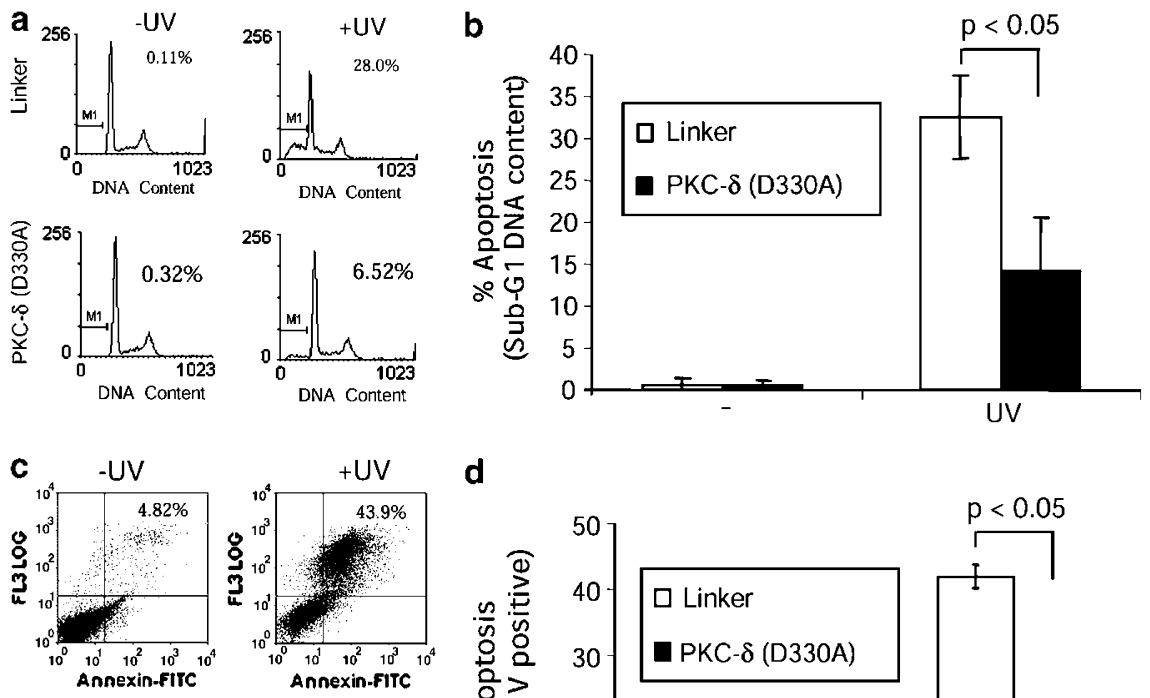

d
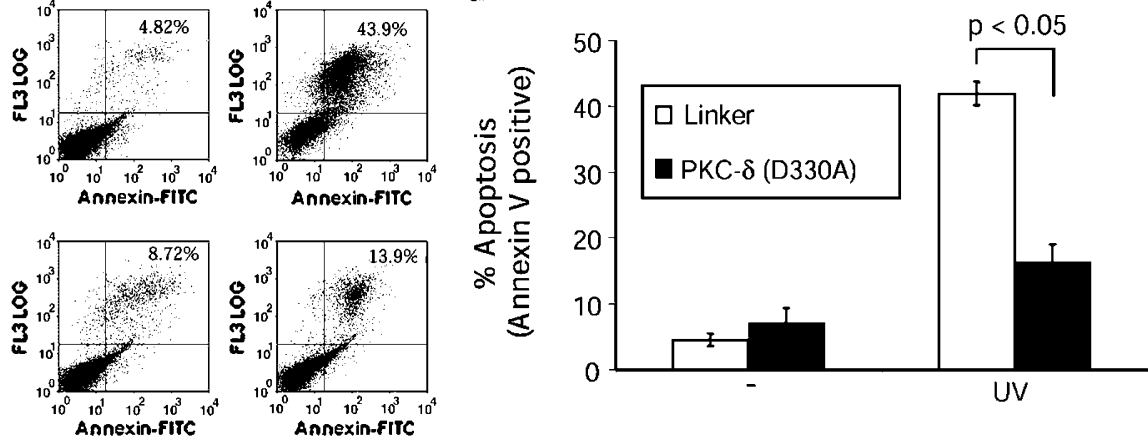

Figure 4 PKC- $\delta(\mathrm{D} 330 \mathrm{~A})$ protects keratinocytes from UV-induced apoptosis. (a) Keratinocytes infected with either Linker virus or PKC- $\delta$ (D330A) virus were exposed to $30 \mathrm{~mJ} / \mathrm{cm}^{2}$ UV and after $18 \mathrm{~h}$, the cells were stained with propidium iodide and analyzed by flow cytometry. The percentage of cells with sub-G1 DNA (apoptotic) is indicated. (b) The sub-G1 DNA content of cells from three independent experiments performed as described in (a) is shown. The error bars denote S.D. ( $n=3$, $P<0.05)$. (c) Keratinocytes infected with either Linker or PKC- $\delta(D 330 A)$ virus were exposed to $30 \mathrm{~mJ} / \mathrm{cm}^{2} \mathrm{UV}$. At $18 \mathrm{~h}$ after UV exposure, the cells were stained with Annexin $V$ and propidium iodide and analyzed by flow cytometry. (d) The percentage of cells undergoing apoptosis (early plus late) from three independent experiments was quantitated and represented in a bar graph. The error bars denote S.D. $(n=3, P<0.05)$

a
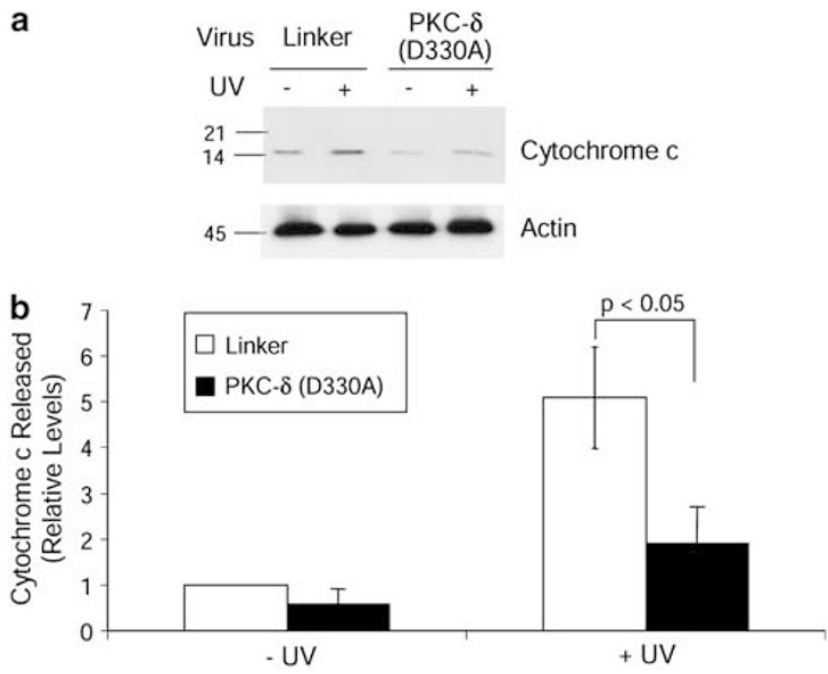

Figure 5 PKC- $\delta(D 330 A)$ inhibits the release of cytochrome $c$ from mitochondria in response to UV. (a) Keratinocytes infected with either Linker virus or PKC- $\delta(D 330 A)$ were left untreated or exposed to $30 \mathrm{~mJ} / \mathrm{cm}^{2}$ UV. After $18 \mathrm{~h}$, the cells were fractionated, and cytosolic fractions were analyzed by Western blotting for cytochrome $c$ and Actin. (b) Cytochrome $c$ release data from four independent experiments as described in (a) were quantitated and are shown in the bar graph. The level of cytosolic cytochrome $c$ in untreated Linkerinfected keratinocytes was normalized to 1.0 for each experiment. The error bars denote S.D. $(n=4, P<0.05)$ of protection was $57.9 \%$ as determined by Rhodamine 123 staining from three independent experiments $(P<0.05)$. Thus, PKC- $\delta$ (D330A) protected normal human keratinocytes from UV-induced loss of mitochondrial membrane potential.

\section{PKC- $\delta$ (D330A) protects keratinocytes from UV-induced loss of $\mathrm{Mcl}-1$}

The UV-induced loss of $\mathrm{Mcl}-1$ is required for release of cytochrome $c$ from mitochondria. To determine if PKC inhibition was able to prevent the downregulation of $\mathrm{Mcl}-1$, keratinocytes were infected with Linker virus, a kinaseinactive PKC- $\delta(\mathrm{K} 378 \mathrm{~A})$ virus, PKC- $\delta$ (D330A) virus, or treated with the general PKC inhibitor GF109203X. At 18h after UV exposure, Mcl-1 levels were detected by Western blotting. Figure 8a shows that PKC- $\delta($ K378A), PKC- $\delta$ (D330A), and GF109203X were able to partially protect keratinocytes from UV-induced downregulation of Mcl-1 as compared to Linkerinfected control cells. An extra band was observed at approximately $66 \mathrm{kDa}$ in the PKC- $\delta$ Western, which could represent a novel cleavage product. However, this band was not reproducible seen elevated in UV-irradiated cell lysates (Figure 9b). The downregulation of $\mathrm{Mcl}-1$ in keratinocytes in response to UV is partly dependent on caspase activity since zVAD was also able to protect keratinocytes from UV-induced 

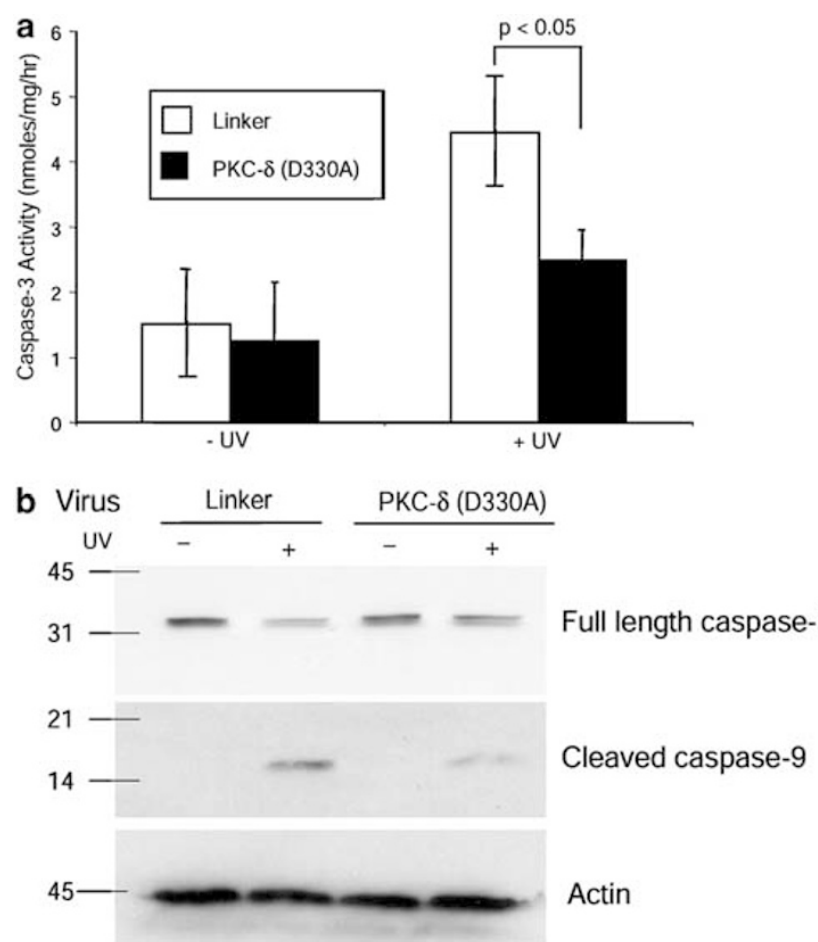

Figure 6 UV-induced caspase-3 activation is blocked by PKC- $\delta$ (D330A). (a) Keratinocytes infected with either Linker virus or PKC- $\delta$ (D330A) virus were exposed to $30 \mathrm{~mJ} / \mathrm{cm}^{2} \mathrm{UV}$ and after $18 \mathrm{~h}$, the caspase activity in the cell lysates was assayed using fluorogenic caspase- 3 substrate Ac-DEVD-AFC. The results from three independent experiments were quantitated. The error bars denote S.D. $(n=3, P<0.05)$. (b) Cell lysates were analyzed by Western blotting for fulllength caspase-3, cleaved caspase-9, and Actin as the loading control

downregulation of $\mathrm{Mcl}-1$, especially at the $18 \mathrm{~h}$ time point (Figure 8b).

\section{PKC- $\delta$ (D330A) prevents the translocation of the endogenous PKC- $\delta$ catalytic fragment to the mitochondria}

Since mitochondrial translocation of the active PKC- $\delta$ catalytic fragment has been implicated in its proapoptotic functions, we examined mitochondrial-enriched fractions from UV-irradiated keratinocytes for the PKC- $\delta$ cleavage product. As shown in Figure 9a, the endogenous PKC- $\delta$ catalytic fragment from Linker-infected control cells was detected in the mitochondria extracts following UV exposure, but overexpression of PKC- $\delta(\mathrm{D} 330 \mathrm{~A})$ prevented the appearance of the $43 \mathrm{kDa}$ mitochondrial PKC- $\delta$ fragment. In Figure $9 \mathrm{~b}$, an analysis of total cell lysates demonstrates that not only is the PKC- $\delta(\mathrm{D} 330 \mathrm{~A})$ mutant not cleaved in UV-irradiated keratinocytes, but cleavage of the endogenous PKC- $\delta$ is blocked in PKC- $\delta(\mathrm{D} 330 \mathrm{~A})$-infected cells. Thus, by not being cleaved and inhibiting the cleavage of endogenous PKC- $\delta$, the PKC- $\delta$ (D330A) mutant was able to prevent mitochondrial accumulation of the PKC- $\delta$ catalytic fragment. Note that the $\sim 45 \mathrm{kDa}$ bands seen in the PKC- $\delta$ (D330A) lysates are present even in the absence of UV, and thus are considered nonspecific bands.
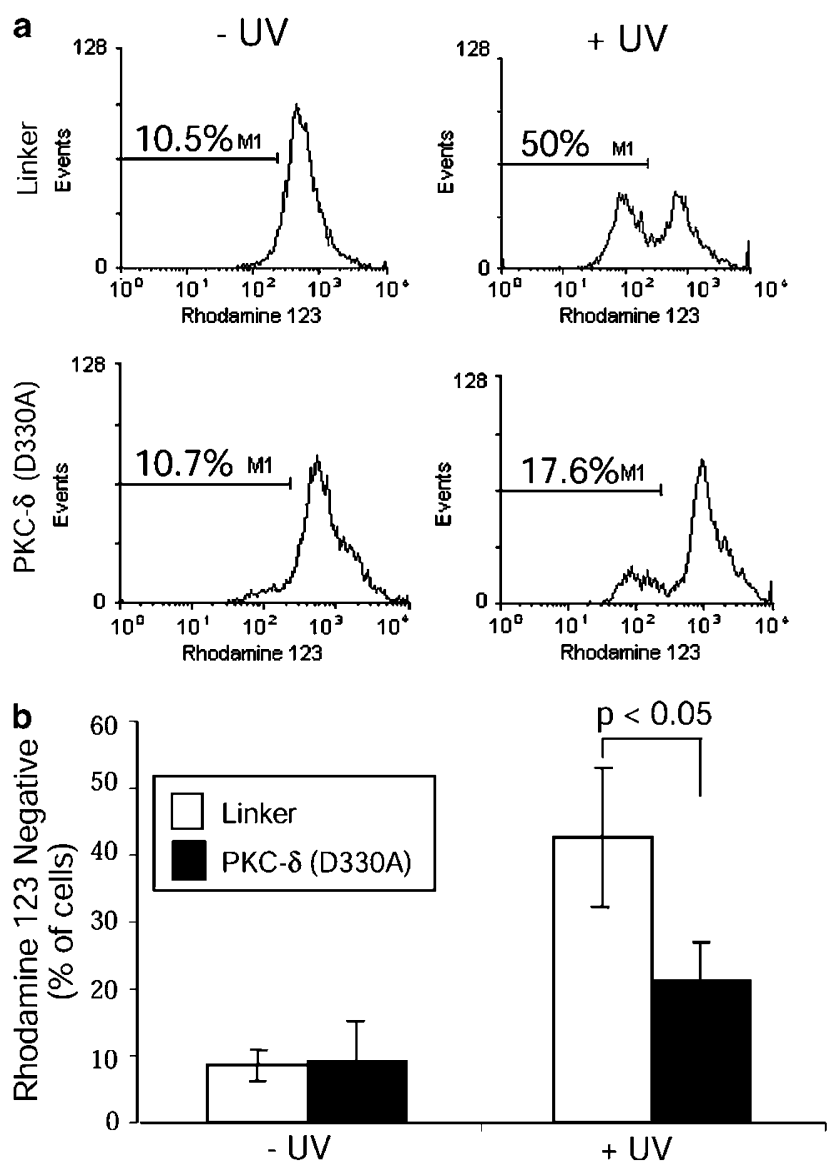

Figure 7 PKC- $\delta(D 330 A)$ protects keratinocytes from UV-induced loss of mitochondrial membrane potential. (a) Keratinocytes infected with either Linker virus or PKC- $\delta(D 330 A)$ virus were exposed to $30 \mathrm{~mJ} / \mathrm{cm}^{2} \mathrm{UV}$ and after $18 \mathrm{~h}$, the cells were stained with Rhodamine 123 and analyzed by flow cytometry. (b) The percent of cells with loss of mitochondrial membrane potential from three independent experiments are quantitated in bar graph form. The error bars denote S.D. $(n=3, P<0.05)$

\section{Discussion}

In human keratinocytes, the induction of apoptosis is a major cellular proofreading mechanism that eliminates damaged cells and protects from skin carcinogenesis. ${ }^{14,15}$ Of the five PKC isoforms expressed in human keratinocytes $(\alpha, \delta, \varepsilon, \eta, \zeta)$, PKC- $\delta$ has a clear proapoptotic function ${ }^{11,13}$ as well as an apparent tumor suppressor function since transgenic mice overexpressing PKC- $\delta$ in the epidermis are resistant to skin tumor promotion by TPA. ${ }^{16}$ Activation of overexpressed PKC$\delta$, or expression of the enzymatically active catalytic fragment induces apoptosis in keratinocytes. ${ }^{10,11}$ Studies using the pan-PKC inhibitor GF109203X ${ }^{11,17}$ have shown that inhibition of total PKC activity rescues cells from UV-induced apoptosis. In this study, we specifically inhibited the caspase-3-dependent cleavage and activation of PKC- $\delta$ by overexpressing a cleavage-resistant mutant form of PKC- $\delta$. PKC- $\delta$ (D330A) blocked many UV-induced apoptotic end points including morphological cell death (Figure 3), sub-G1 DNA (Figures 4a and b), activation of caspase-3 and caspase-9 (Figure 6), and the loss of mitochondrial membrane potential (Figure 7). Furthermore, PKC- $\delta(\mathrm{D} 330 \mathrm{~A})$ inhibited the loss of $\mathrm{Mcl}-1$ 
a

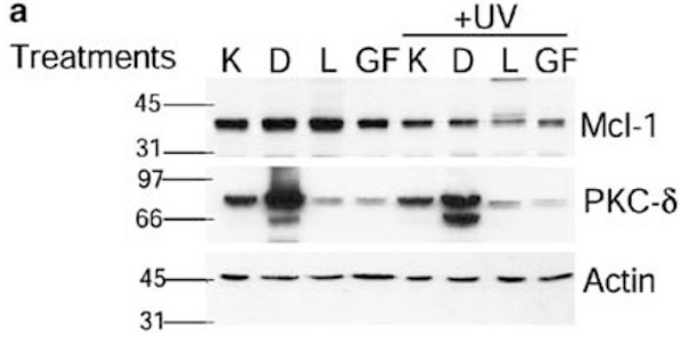

b

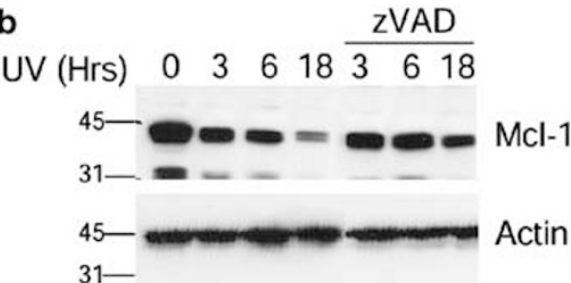

Figure 8 PKC- $\delta(\mathrm{D} 330 \mathrm{~A})$ protects keratinocytes from loss of Mcl-1 during UV apoptosis. (a) Keratinocytes were infected with PKC- $\delta(\mathrm{K} 378 \mathrm{~A})$ virus (K), PKC$\delta(\mathrm{D} 330 \mathrm{~A})$ virus (D), Linker virus (L), or treated with the PKC inhibitor GF109203X (GF) as indicated and exposed to UV. After $18 \mathrm{~h}$, lysates were prepared for Mcl-1 Western blotting. Note the reduction in Mcl-1 levels by UV (Linker + UV) is partially blocked by PKC- $\delta$ (K378A), PKC- $\delta$ (D330A), and GF109203X. Overexpression of the mutant PKC- $\delta$ forms was verified by PKC $\delta$ Western blot. (b) Mcl-1 protein levels were detected by Western blotting at $0,3,6$, and $18 \mathrm{~h}$ after UV exposure in the presence and absence of ZVAD. Note the early ( 3 and $6 \mathrm{~h}$ ) and late (18 $\mathrm{h}$ ) reduction in Mcl-1 levels. ZVAD protected from Mcl-1 loss primarily at the $18 \mathrm{~h}$ time point

(Figure 8) and the release of cytochrome $c$ (Figure 5), early events in the UV-apoptotic pathway.

$\mathrm{PKC}-\delta$ is a widely expressed PKC isoform that is activated allosterically by TPA or DAG generated from lipid hydrolysis via binding to its $\mathrm{C} 1$ domain, or by proteolytic cleavage in its hinge region to generate an active catalytic fragment domain. $6,11,18$ Translocation of PKC- $\delta$ from the cytosol to the membrane does not occur in keratinocytes undergoing UV apoptosis: ${ }^{13}$ however, rapid translocation has been observed in JB6 cells suggestive of DAG-mediated activation. ${ }^{19}$ The PKC- $\delta$ (D330A) mutant had a functional $C 1$ domain and could be activated by TPA but not caspase-3 (Figure 2), indicating that activation of PKC- $\delta$ by DAG at the $\mathrm{C} 1$ domain is not required for UV apoptosis in keratinocytes. The results from this study using the caspase cleavage resistant form of PKC- $\delta$ indicate that the activation of PKC- $\delta$ by proteolytic cleavage is the relevant mechanism of activation of PKC- $\delta$ in keratinocytes undergoing UV apoptosis.

A critical event leading to the activation of PKC- $\delta$ following UV exposure is the release of cytochrome $c$ from the mitochondria. Inhibition of PKC- $\delta$ cleavage and activation with $\mathrm{PKC}-\delta(\mathrm{D} 330 \mathrm{~A})$ partially inhibited cytochrome $c$ release (Figure 5). The release of cytochrome $c$ following UV exposure is mediated by Bax and Bak, and the early downregulation of the antiapoptotic protein $\mathrm{Mcl}-1$ is also necessary. ${ }^{20,21}$ We found that the downregulation of $\mathrm{Mcl}-1$ by UV was partially prevented by PKC- $\delta$ (D330A) (Figure 8). Mcl1 itself is a substrate of caspase-3, and some of the protection from $\mathrm{Mcl}-1$ loss is probably due to inhibition of caspase activation by PKC- $\delta$ (D330A) since $z V A D$ also protected from
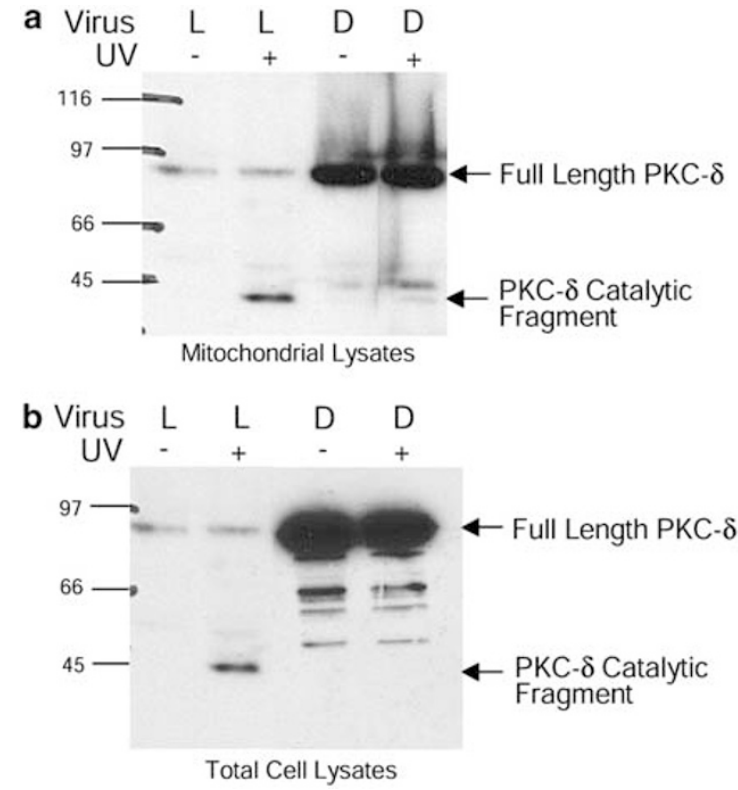

Figure 9 PKC- $\delta(\mathrm{D} 330 \mathrm{~A})$ prevents UV-induced translocation of the PKC- $\delta$ catalytic fragment to mitochondria. (a) Keratinocytes were infected with either Linker (L) virus or PKC- $\delta(\mathrm{D} 330 \mathrm{~A})(\mathrm{D})$ virus and were left untreated or exposed to UV. After $18 \mathrm{~h}$, mitochondrial lysates were prepared and PKC- $\delta$ levels detected by Western blotting. Note that the $43 \mathrm{kDa}$ PKC- $\delta$ catalytic fragment is not present in the mitochondria of PKC- $\delta(\mathrm{D} 330 \mathrm{~A})$-expressing cells exposed to UV. (b) Total cell lysates prepared from keratinocytes treated as in (a) were blotted for PKC- $\delta$. Note that PKC- $\delta(\mathrm{D} 330 \mathrm{~A})$ is not cleaved in UV-irradiated cells, and that PKC$\delta(\mathrm{D} 330 \mathrm{~A})$ also prevented the cleavage of endogenous PKC- $\delta$

Mcl-1 loss at later time points. ${ }^{22}$ Thus, PKC- $\delta$ cleavage and activation can feed back to reduce the antiapoptotic protein $\mathrm{Mcl}-1$ involved in initiating cytochrome $c$. However, because PKC- $\delta$ cleavage and activation occur after the initial cytochrome $c$ release, protecting from $\mathrm{Mcl}-1$ loss cannot completely block cytochrome $c$ release (Figure 5).

Once cytochrome $c$ is released, it participates in the formation of the apoptosome resulting in activation of the caspase cascade including caspase-3. Active caspase-3 then cleaves PKC- $\delta$ to generate the active catalytic fragment, which localizes to the mitochondria. ${ }^{10,11} \mathrm{PKC}-\delta$ is involved in a positive feedback loop with caspase-3 in various cell systems, ${ }^{17,23-25}$ and our results indicate that cleavage of PKC- $\delta$ is required. The exact mechanisms involved in the activation of caspase- 3 by PKC- $\delta$ are not yet known. ${ }^{26}$ However, we showed that the caspase-3 cleavage resistant PKC- $\delta(\mathrm{D} 330 \mathrm{~A})$ inhibits the generation and translocation of the catalytic domain of PKC- $\delta$ to the mitochondria (Figure 9), and this may disrupt the positive feedback loop between the caspase activation and PKC- $\delta$. Consistent with this, the PKC$\delta(\mathrm{D} 330 \mathrm{~A})$ mutant was able to partially prevent caspase activation in response to UV (Figure 6). Thus, our working model positions PKC- $\delta$ as a critical caspase- 3 substrate, which when cleaved, translocates to the mitochondria to enhance the release of cytochrome $c$ and caspase-9/ caspase-3 activation, thereby promoting apoptosis. The caspase-resistant PKC- $\delta$ (D330A) inhibits apoptosis by competitively inhibiting endogenous $\mathrm{PKC}-\delta$ cleavage, thus preventing the formation and mitochondrial translocation of the 
active PKC- $\delta$ catalytic fragment. We estimate that at least $50 \%$ of UV-induced apoptosis requires this PKC- $\delta$-positive feedback since we consistently see greater than $50 \%$ protection from UV apoptosis when PKC- $\delta$ cleavage and activation are prevented (Figures 4 and 7 ). PKC- $\delta$ activation is also associated with the loss of mitochondrial membrane potential. This is a late event in UV apoptosis, and PKC$\delta(\mathrm{D} 330 \mathrm{~A})$ was able to protect keratinocytes from UV-induced loss of mitochondrial membrane potential.

Overexpression of PKC- $\delta$ in the epidermis can suppress skin tumor formation by TPA in mice, ${ }^{16}$ and depletion of PKC- $\delta$ in rat fibroblasts leads to tumor promotion, ${ }^{27}$ indicating that PKC- $\delta$ has a tumor suppressor function. Since activation of overexpressed full-length PKC- $\delta$ can induce apoptosis, the tumor suppression in PKC- $\delta$ transgenic mice may be due to the induction of apoptosis. In keratinocytes with ras $^{\mathrm{Ha}}$ activated, PKC- $\delta$ is inhibited by downregulation in human keratinocytes $^{28-30}$ or by tyrosine phosphorylation through Src and Fyn in mouse keratinocytes. ${ }^{28-30}$ Inhibition of UV-induced apoptosis by $\mathrm{PKC}-\delta(\mathrm{D} 330 \mathrm{~A})$ resulted in enhanced survival and growth of keratinocytes (Figure $3 \mathrm{~b}$ ), and thus cells with reduced or inactive PKC- $\delta$ have a selective growth advantage over cells with functional PKC- $\delta$, consistent with the tumor suppressor function of PKC- $\delta$. In light of our results demonstrating that the cleavage/activation of PKC- $\delta$ in keratinocytes is an important event required for UV apoptosis, the inactivation of PKC- $\delta$ by Ras activation in premalignant keratinocytes could provide a selective growth advantage to keratinocytes repeatedly exposed to genotoxic doses of UV radiation from the sun.

\section{Materials and Methods}

\section{Antibodies and chemicals}

For the detection of PKC- $\delta$ by Western blotting, a carboxyl-terminal PKC- $\delta$ antibody was used at a dilution of 1:4000 (sc-937, Santa Cruz Biotechnology, Santa Cruz, CA, USA). For cytochrome $c$ detection, an antibody (\#630105, Clontech, Palo Alto, CA, USA) at 1:500 dilution was used. A cleaved caspase-9 antibody (9501S, Cell Signaling, Beverly, MA, USA) and a caspase-3 antibody (sc-7272, Santa Cruz, CA, USA) at 1:500 dilution were used. For the detection of Mcl-1, an Mcl-1 antibody was used at a dilution of 1:500 (sc-819, Santa Cruz Biotechnology, Santa Cruz, CA, USA). For caspase assays, the fluorogenic substrate Ac-DEVD-AFC for caspase-3 (Enzyme Systems Products, Livermore, CA, USA) was prepared at $20 \mathrm{mM}$ stock in $\mathrm{Me}_{2} \mathrm{SO}$. The PKC inhibitor GF109203X (Alexis Biochemicals, San Diego, CA, USA) was used at $5 \mu \mathrm{M}$.

\section{Cell culture and UV treatment}

Normal human epidermal keratinocytes were isolated from neonatal foreskins following routine circumcision as previously described. ${ }^{13}$ Each experiment was performed on the cells isolated from a single foreskin and were used at passage 2 . Keratinocytes were irradiated with a Panelite Unit (Ultralite Enterprises, Inc., Lawrenceville, GA, USA) equipped with four UVB bulbs (FS36T12/UVB-VHO), which have the majority of their output in the UVB range $(\sim 65 \%)$, with minor output in the UVA and UVC wavelengths ( $\sim 34$ and $\sim 1 \%$, respectively). The cells were exposed with the dish lids removed for the indicated doses, with a $30 \mathrm{~mJ} / \mathrm{cm}^{2}$ dose requiring about 1-min exposure. The UV dose was monitored with an
International Light Inc. (Newburyport, MA, USA) radiometer fitted with a UVB detector. For Figure $3 b$, the growth of cells after UV irradiation was monitored by counting viable cells using Trypan Blue exclusion.

\section{Retrovirus construction, production, and infection}

The PKC- $\delta(\mathrm{D} 330 \mathrm{~A})$ mutant containing a mutation of $\mathrm{Asp}^{330}$ to Ala was generated using the QuikChange Site-Directed Mutagenesis kit (Stratagene, La Jolla CA, USA). The primers MFD 30: 5'-GCT GGG GAG GAT ATG CAA GCC AAC AGT GGG ACC-3' and MFD 31: $5^{\prime}$-GGT CCC ACT GTT GGC TTG CAT ATC CTC CCC AGC-3' were used with the pKSPKC- $\delta$ template. ${ }^{11}$ The mutated base is underlined. This cleavage resistant mutant form of PKC- $\delta$ was cloned into LZRS retroviral vector between the EcoR1 and Not1 sites. ${ }^{31}$ After cloning, the insert was verified by sequencing and the presence of the mutation confirmed. For retrovirus production, LZRS PKC- $\delta$ (D330A) DNA was transfected into PhoenixAmpho retroviral packaging cell line using calcium phosphate as described. ${ }^{32}$ Packaging cells were selected and expanded in the presence of $1 \mu \mathrm{g} / \mathrm{ml}$ puromycin, and virus was harvested from confluent dishes cultured for $24-48 \mathrm{~h}$ at $32^{\circ} \mathrm{C}$. In some experiments, a kinase-inactive PKC$\delta(\mathrm{K} 378 \mathrm{~A})$ virus was used. For infection, normal keratinocytes were plated in six-well dishes at $10^{5}$ cells per well, and the following day viral supernatant was added in the presence of $4 \mu \mathrm{g} / \mathrm{ml}$ polybrene (hexadimethrine bromide, Sigma). The cells were infected by spinning the plates at $300 \times \mathrm{g}$ for $1 \mathrm{~h}$ at $32^{\circ} \mathrm{C}$, and the viral supernatants replaced with fresh Medium 154. The day after infection, cells were washed two times with phosphate-buffered saline and fed with Medium 154.

\section{Cell fractionation and immunoblotting}

Total cell lysates for immunoblotting were prepared by lysing cells in $20 \mathrm{mM}$ Tris- $\mathrm{HCl}, \mathrm{pH} 7.5,1 \%$ Triton X-100, $5 \mathrm{mM}$ EDTA, $40 \mu \mathrm{g} / \mathrm{ml}$ leupeptin, $1 \mu \mathrm{M}$ pepstatin, $1 \mathrm{mM}$ AEBSF. The lysates were spun in a microcentrifuge for $10 \mathrm{~min}$ at $4^{\circ} \mathrm{C}$, and $20 \mu \mathrm{g}$ protein from the supernatant was taken for analysis. The proteins were run on SDS polyacrylamide gels, transferred to nitrocellulose, and stained with Ponceau $S$ to ensure protein equal loading. The membranes were blocked with $5 \%$ milk in $20 \mathrm{mM}$ Tris- $\mathrm{HCl}, \mathrm{pH} 7.6,150 \mathrm{mM} \mathrm{NaCl}$ (TBS), stained with primary antibody and horseradish peroxidase-conjugated secondary antibody for $1 \mathrm{~h}$ each and extensively washed in TBS, $0.05 \%$ Tween-20. Proteins were detected using the ECL detection kit (Amersham Life Sciences, Piscataway, NJ, USA).

For cytosol isolation, cells were trypsinized, washed in PBS, and suspended in $10 \mathrm{mM}$ HEPES, pH 7.5, $250 \mathrm{mM}$ sucrose, $10 \mathrm{mM} \mathrm{KCl}$, $1.5 \mathrm{mM} \mathrm{MgCl}$, $1 \mathrm{mM}$ EGTA, $1 \mathrm{mM}$ EDTA, $1 \mathrm{mM}$ dithiothreitol, and $1 \times$ Complete Protease Inhibitor Cocktail (Boehringer Mannheim). Digitonin was added to $0.05 \%$, and the cells were incubated for $2 \mathrm{~min}$ at room temperature. The cells were then spun at $750 \times \mathrm{g}$ for $5 \mathrm{~min}$ at $4{ }^{\circ} \mathrm{C}$ to pellet unbroken cells and nuclei, and the supernatant was taken and spun at $10000 \times \mathrm{g}$ at $4^{\circ} \mathrm{C}$ for $25 \mathrm{~min}$. This supernatant was taken as the cytosolic fraction and the pellet was the mitochondrial fraction.

\section{Caspase assay}

For caspase assays, cells were trypsinized and combined with floating cells. The cells were lysed in $2 \times$ caspase-lysis buffer: $25 \mathrm{mM}$ HEPES$\mathrm{NaOH}, \mathrm{pH} 7.4,10 \%$ sucrose, $0.1 \%$ CHAPS, $2 \mathrm{mM}$ EDTA, and $5 \mathrm{mM}$ dithothreitol. Cells were spun for $5 \mathrm{~min}$ in a microcentrifuge and then the protein concentration was estimated by the Bradford method. Intotal, $50 \mu \mathrm{g}$ of total protein was used per sample and mixed with $2 \times$ caspase 
assay buffer: $25 \mathrm{mM}$ HEPES-NaOH, pH 7.4, $5 \mathrm{mM}$ DTT, and $100 \mu \mathrm{M}$ of the fluorogenic caspase-3 substrate Ac-DEVD-AFC. After incubation for $18 \mathrm{~h}$ at $37^{\circ} \mathrm{C}$, the fluorimetric detection of cleaved AFC product was performed on CytoFlour Multi-Well Plate Reader Series 4000 (PerSeptive Biosystems) at $400 \mathrm{nM}$ excitation and $530 \mathrm{nM}$ emission filter.

\section{Flow cytometry}

Apoptosis was measured by propidium iodide staining and flow cytometry as previously described. ${ }^{13}$ Rhodamine 123 staining and flow cytometry to determine loss of mitochondrial membrane potential was performed as previously described. ${ }^{2}$

Annexin $\mathrm{V}$ staining was performed using an Annexin V-FITC kit (Beckman Coulter Inc., Fullerton, CA, USA). At $18 \mathrm{~h}$ after UV exposure, the floaters were combined with the cells obtained after trypsinization and spun for $5 \mathrm{~min}$ at $20^{\circ} \mathrm{C}$. The cell pellets were then washed with ice-cold phosphate-buffered saline with $\mathrm{Ca}^{2+}$ and $\mathrm{Mg}^{2+}$. The cell pellets were then suspended in $100 \mu \mathrm{l}$ of $1 \times$ diluted binding buffer at $4^{\circ} \mathrm{C}$. In all, $1 \mu \mathrm{l}$ of Annexin $V$ and $5 \mu$ of dissolved propidium iodide were then added per sample and incubated at $4^{\circ} \mathrm{C}$ in the dark for $10 \mathrm{~min}$. Ice-cold $1 \times$ diluted binding buffer (400) was then added per sample tube and mixed gently. The samples were analyzed by flow cytometry immediately after Annexin V staining.

\section{PKC- $\delta$ immunoprecipitation kinase assay}

Keratinocytes were infected with LZRS-Linker virus or LZRS-PKC$\delta(\mathrm{D} 330 \mathrm{~A})$ virus at $20 \%$ confluency. When the cells reached $80-90 \%$ confluency, they were UV irradiated with a dose of $30 \mathrm{~mJ} / \mathrm{cm}^{2}$ or treated with $2 \mu \mathrm{M}$ TPA for $15 \mathrm{~min}$. Protein $(500 \mu \mathrm{g})$ was used per sample for overnight immunoprecipitation with PKC- $\delta$ (sc-937, Santa Cruz Biotech, CA, USA) and a kinase reaction was performed as previously described. ${ }^{13}$

\section{Acknowledgements}

We thank all members of the Skin Cancer Research Program for their input into this project, especially Shalini S Tibudan and Drs. Leonid A Sitailo, Jian-Zhong Qin, and Brian J Nickoloff. This work was supported in part by NIH Grant CA83784 (MF Denning).

\section{References}

1. Thornberry NA and Lazebnik Y (1998) Caspases: enemies within. Science 281: 1312-1316

2. Sitailo LA, Tibudan SS and Denning MF (2002) Activation of caspase-9 is required for UV-induced apoptosis of human keratinocytes. J. Biol. Chem. 277: 19346-19352

3. Rehemtulla A, Hamilton CA, Chinnaiyan AM and Dixit VM (1997) Ultraviolet radiation-induced apoptosis is mediated by activation of CD-95 (Fas/APO-1). J. Biol. Chem. 272: 25783-25786

4. Aragane Y, Kulms D, Metze D, Wilkes G, Poppelmann B, Luger TA and Schwartz T (1998) Ultraviolet light induces apoptosis via direct activation of CD95 (Fas/APO-1) independently of its ligand CD95L. J. Cell Biol. 140: 171-182

5. Leverkus M, Yaar M and Gilchrest BA (1997) Fas/Fas ligand interaction contributes to UV-induced apoptosis in human keratinocytes. Exp. Cell Res. 232: 255-262

6. Ghayur T, Hugunin M, Talanian RV, Ratnofsky S, Quinlan C, Emoto Y, Pandey P, Datta R, Huang Y, Kharbanda S, Allen H, Kamen R, Wong W and Kufe D (1996) Proteolytic activation of protein kinase C delta by an ICE/CED 3-like protease induces characteristics of apoptosis. J. Exp. Med. 184: 2399-2404

7. Sakurai $Y$, Onishi $Y$, Tanimoto $Y$ and Kizaki $H$ (2001) Novel protein kinase $C$ delta isoform insensitive to caspase-3. Biol. Pharm. Bull. 24: 973-977

8. Emoto $\mathrm{Y}$, Manome $\mathrm{Y}$, Meinhardt G, Kisaki H, Kharbanda S, Robertson M, Ghayur T, Wong WW, Kamen R, Weichselbaum R and Kufe D (1995) Proteolytic activation of protein kinase $\mathrm{C}$ delta by an ICE-like protease in apoptotic cells. EMBO J. 14: 6148-6156

9. Datta R, Kojima H, Yoshida K and Kufe D (1997) Caspase-3-mediated cleavage of protein kinase $\mathrm{C}$ theta in induction of apoptosis. J. Biol. Chem. 272: 20317-20320

10. Li L, Lorenzo PS, Bogi K, Blumberg PM and Yuspa SH (1999) Protein kinase C delta targets mitochondria, alters mitochondrial membrane potential, and induces apoptosis in normal and neoplastic keratinocytes when overexpressed by an adenoviral vector. Mol. Cell. Biol. 19: 8547-8558

11. Denning MF, Wang Y, Alkan S, Nickoloff BJ and Qin JZ (2002) Caspase activation and disruption of mitochondrial membrane potential during UV radiation-induced apoptosis of human keratinocyte requires activation of protein kinase C. Cell Death Diff. 9: 40-52

12. Mizuno K, Noda K, Araki T, Imaoka T, Kobayashi Y, Akita Y, Shimonaka M, Kishi S and Ohno S (1997) The proteolytic cleavage of protein kinase C isotypes, which generates kinase and regulatory fragments, correlates with Fas-mediated and 12-0-tetradecanoyl-phorbol-13-acetate-induced apoptosis. Eur. J. Biochem. 250: 7-18

13. Denning MF, Wang Y, Nickoloff BJ and Wrone-Smith T (1998) Protein kinase $C$ $\delta$ is activated by caspase-dependent proteolysis during ultraviolet radiation-induced apoptosis of human keratinocytes. J. Biol. Chem. 273: 29995-30002

14. Ziegler A, Jonason AS, Leffell DJ, Simon JA, Sharma HW, Kimmelman J, Remington L, Jacks T and Brash DE (1994) Sunburn and p53 in the onset of skin cancer. Nature 372: $773-776$

15. Pena JC, Rudin CM and Thompson CB (1998) A BCl- $\mathrm{x}_{\mathrm{L}}$ transgene promotes malignant conversion of chemically initiated skin papillomas. Cancer Res. 58: 2111-2116

16. Reddig PJ, Dreckschimdt NE, Ahrens H, Simsiman R, Tseng CP, Zou J, Oberly TD and Verma AK (1999) Transgenic mice overexpressing protein kinase $C$ delta in the epidermis are resistant to skin tumor promotion by 12-Otetradecanoylphorbol-13-acetate. Cancer Res. 59: 5710-5718

17. Reyland ME, Anderson SM, Matassa AA, Barzen KA and Quissell DO (1999) Protein kinase $C$ delta is essential for etoposide-induced apoptosis in salivary gland acinar cells. J. Biol. Chem. 274: 19115-19123

18. Stabel S and Parker PJ (1991) Protein kinase C. Pharmacol. Ther. 51: 71-95

19. Chen N, Ma W, Huang $C$ and Dong Z (1999) Translocation of protein kinase $C$ epsilon and protein kinase $\mathrm{C}$ delta to membrane is required for ultraviolet $\mathrm{B}$ induced activation of mitogen-activated protein kinases and apoptosis. J. Biol. Chem. 274: 15389-15394

20. Wei MC, Zong WX, Cheng EH, Lindsten T, Panoutsakopoulou V, Ross AJ, Roth KA, MacGregor GR, Thompson CB and Korsmeyer SJ (2001) Proapoptotic BAX and BAK: a requisite gateway to mitochondrial dysfunction and death. Science 292: 727-730

21. Nijhawan D, Fang M, Traer E, Zhong Q, Gao W, Du F and Wang X (2003) Elimination of Mcl-1 is required for the initiation of apoptosis following ultraviolet irradiation. Genes Dev. 17: 1475-1486

22. Snowden RT, Sun XM, Dyer MJ and Cohen GM (2003) Bisindolylmaleimide IX is a potent inducer of apoptosis in chronic lymphocytic leukaemic cells and activates cleavage of Mcl-1. Leukemia 17: 1981-1989

23. Anantharam V, Kitazawa M, Wagner J, Kaul S and Kanthasamy AG (2002) Caspase-3-dependent proteolytic cleavage of protein kinase $C$ delta is essential for oxidative stress-mediated dopaminergic cell death after exposure to methylcyclopentadienyl manganese tricarbonyl. J. Neurosci. 22: 1738-1751

24. Blass M, Kronfeld I, Kazimirsky G, Blumberg PM and Brodie C (2002) Tyrosine phosphorylation of protein kinase $C$ delta is essential for its apoptotic effect in response to etoposide. Mol. Cell. Biol. 22: 182-195

25. Basu A and Akkaraju G (1999) Regulation of caspase activation and cisdiamminedichloroplatinum(II)-induced cell death by protein kinase $\mathrm{C}$. Biochemistry 38: 4245-4251

26. Brodie $C$ and Blumberg PM (2003) Regulation of cell apoptosis by protein kinase $C$ delta. Apoptosis 8: 19-27 
PKC- $\delta$ in UV apoptosis AM D'Costa and MF Denning

27. Lu Z, Hornia A, Jiang YW, Zang Q, Ohno S and Foster DA (1997) Tumor promotion by depleting cells of protein kinase $C$ delta. Mol. Cell Biol. 17: 34183428

28. Denning MF, Dlugosz AA, Threadgill DW, Magnuson T and Yuspa SH (1996) Activation of the epidermal growth factor receptor signal transduction pathway stimulates tyrosine phosphorylation of protein kinase $\mathrm{C}$ delta. J. Biol. Chem. 271: 5325-5331

29. Geiges D, Marks F and Gschwendt M (1995) Loss of protein kinase C delta from human HaCaT keratinocytes upon ras transfection is mediated by TGF alpha. Exp. Cell Res. 219: 299-303
30. Denning MF, Dlugosz AA, Howett MK and Yuspa SH (1993) Expression of an oncogenic ras ${ }^{\mathrm{Ha}}$ gene in murine keratinocytes induces tyrosine phosphorylation and reduced activity of protein kinase C delta. J. Biol. Chem. 268: 2607926081

31. Kinsella TM and Nolan GP (1996) Episomal vectors rapidly and stably produce high-titer recombinant retrovirus. Hum. Gene Ther. 7: 1405-1413

32. Qin JZ, Bacon P, Chaturvedi V and Nickoloff BJ (2001) Role of NF-kappaB activity in apoptotic response of keratinocytes mediated by interferon-gamma, tumor necrosis factor-alpha, and tumor-necrosis-factor-related apoptosisinducing ligand. J. Invest. Dermatol. 117: 898-907 